\title{
Evaluation of the Effect of Sewage Irrigation on Groundwater
}

\author{
Xiuli Li*† and Xiaoyu Li** \\ *School of Water Conservancy, North China University of Water Resources and Electric Power, \\ Zhengzhou 450045, China \\ **Hydrology Bureau of Yellow River Conservancy Commission, Zhengzhou 450004, China \\ $\dagger$ Corresponding author: Xiuli Li; lixiuli96@163.com
}

Nat. Env. \& Poll. Tech. Website: www.neptjournal.com

Received: 07-12-2019

Revised: 21-12-2019

Accepted: 28-03-2020

\section{Key Words:}

Sewage irrigation

Groundwater

Water quality evaluation

Fuzzy comprehensive

evaluation

Evaluation standard

\begin{abstract}
In areas with water resources shortage, sewage irrigation can alleviate the contradiction between supply and demand for water. However, long-term use of sewage irrigation will affect soil, crops and groundwater. In this paper, irrigation water and groundwater in different irrigation source areas were sampled and analysed respectively to study the effect of sewage irrigation on groundwater. The irrigation water was evaluated for $\mathrm{Cl}^{-}, \mathrm{Cd}, \mathrm{Pb}, \mathrm{Cr}^{6+}, \mathrm{As}, \mathrm{Cu}, \mathrm{F}^{-}, \mathrm{TP}, \mathrm{Hg}$ and $\mathrm{Zn}$ as standards for irrigation water quality which along with Nemerow index method were used for comprehensive evaluation. The result of the evaluation is that the water quality of the reclaimed water, domestic sewage and mixed sewage meet the requirements of the agricultural irrigation, and the industrial sewage pollution index is relatively high and less suitable for agricultural irrigation. The fuzzy comprehensive evaluation method was adopted to evaluate groundwater quality, using Quality Standard for Ground Water (GBT148482017) as evaluation factor standard and ammonia nitrogen $\left(\mathrm{NH}_{3}-\mathrm{N}\right)$, chloride $\left(\mathrm{Cl}^{-}\right)$, nitrate $\left(\mathrm{NO}_{3}-\mathrm{N}\right)$ and nitrite $\left(\mathrm{NO}_{2}-\mathrm{N}\right)$ as evaluation indicators. The results of the evaluation showed that the water quality of 2 monitor wells among the 11 monitor wells was within Category II, 6 within Category III, and 3 within Category IV. With regards to the influence of different irrigation sources on groundwater, the comprehensive evaluation results are reasonable as well. According to the comprehensive membership grades, it can be concluded that the influence of different water sources on groundwater quality, in turn, is reclaimed water $<$ domestic sewage $<$ mixed sewage $<$ industrial sewage. The evaluation results are in line with the actual situation in the study area.
\end{abstract}

\section{INTRODUCTION}

The shortage of water resources restricts the development of economy, and the limited water resources usually first meet the demand of domestic and industrial use, and then agriculture, which undoubtedly makes the phenomenon of agricultural water shortage more serious. China is a big agricultural country dominated by irrigation. According to the China Water Resources Bulletin, agricultural water consumption accounted for $61.4 \%$ of total water consumption in 2018. At present, the water shortage in agriculture is becoming more and more serious as agriculture water is being squeezed continuously to meet domestic and industrial water demand. The only way to solve agricultural water shortage is "increasing income and decreasing expenditure" to achieve the benign development of agriculture. Wastewater recovery is considered as a major way to solve the problem of agricultural water shortage. Using sewage effluent for irrigation, on the one hand, solves the problem of discharge of massive sewage generated in the process of domestic and industrial use of water resources in areas without sewage treatment plants, on the other hand, alleviates the problem of agricultural water shortage. However, there are still many problems concerning the use of sewage for agricultural irrigation. While some nutritive elements in the sewage can add to the content of nutrients in the soil, long-term use of sewage for irrigation will affect the soil and the quality of groundwater (Wen 2012). Massive pollutants and substances in the sewage that hardly decompose will remain in the soil, accumulate and enter into groundwater environment along with agricultural irrigation \& water supply, which pollutes and influences the groundwater (Wan et al. 2015). Evaluating the quality of groundwater by testing and analysing the chemical indicators provides a scientific basis for the protection and sustainable exploitation of water resources.

\section{MATERIALS AND METHODS}

\section{General Situation of the Study Areas}

As there are quite many irrigation areas adopting sewage irrigation in the North China Plains, where there is a serious shortage of water, in this article, several irrigation areas in a city of North China Plain with a 10+ year history of using different water quality for irrigation were chosen and sam- 
pled to study the influence of irrigation with different water quality on groundwater. Based on the different water quality of the sewage adopted in the irrigation areas, the irrigation areas are divided into domestic sewage irrigation area, mixed sewage irrigation area, industrial sewage irrigation area and reclaimed water irrigation area.

\section{Sample Collection and Water Analysis}

In the study area, irrigation water sampling locations and groundwater sampling locations were set respectively based on the irrigation water sources and the actual situation of various irrigation areas. For irrigation water sources, the sampling locations were set at the intake of various irrigation areas; and for groundwater, 11 groundwater monitor wells in different places of the studied areas were chosen as sampling locations. The selection of sampling locations takes account of irrigation areas with different water quality, as 2 wells were chosen from the reclaimed water irrigation area, 2 from the domestic sewage irrigation area, 3 wells from the mixed sewage irrigation area, and 4 wells from the industrial sewage irrigation area.

To reduce water sample errors, pre-sampling and post-sampling were carried out strictly in line with Water Quality Sampling-Technical Regulation of the Preservation and Handling of Samples (HJ 493-2009). Respective analysis methods were adopted to test various indicators.

Major monitoring indicators for the irrigation water source test include $\mathrm{Cl}^{-}, \mathrm{Cd}, \mathrm{Pb}, \mathrm{Cr}^{6+}, \mathrm{As}, \mathrm{Cu}, \mathrm{F}^{-}, \mathrm{TP}, \mathrm{Hg}$ and $\mathrm{Zn}$; and major monitoring indicators for the groundwater include: chlorine ions, ammonia nitrogen, nitrates, nitrite and heavy metals.

All indicators in the water samples were tested and analysed in strict accordance with respective methods. Table 1 provides the specific tests and analysis methods of each indicator.

\section{RESULTS AND ANALYSIS}

Evaluation of irrigation water quality: The quality of all kinds of irrigation water in the study area was evaluated following Standards for Irrigation Water Quality (GB50842005). Indicators such as $\mathrm{Cl}^{-}, \mathrm{Cd}, \mathrm{Pb}, \mathrm{Cr}^{6+}, \mathrm{As}, \mathrm{Cu}, \mathrm{F}^{-}, \mathrm{TP}$, $\mathrm{Hg}$ and $\mathrm{Zn}$ were chosen as evaluation factors. Pollution index of every single indicator was calculated with the following calculation formula:

$$
I=\frac{C_{i}}{C_{0}}
$$

Where, $\mathrm{C}_{\mathrm{i}}$ implies the water quality indicator of various sampling locations; $\mathrm{C}_{0}$ implies the standard limit of Standards for Irrigation Water Quality. Table 2 gives the calculation results of the pollution index of every single indicator of different irrigation water quality.

Based on the data from Table 2, various evaluation indicators of reclaimed water, domestic sewage, mixed sewage, industrial sewage were compared and analysed against the limits of Standards for Irrigation Water Quality: (1) all single indicators of reclaimed water are within the standards except for $\mathrm{Cd}$ which is 1.2 times that of the standard; (2) in domestic sewage, $\mathrm{Pb}$ is twice that of the standard, $\mathrm{Hg}$ reaches the critical value, and other indicators are within the standards; (3) in mixed sewage, $\mathrm{Cl}^{-}$is 1.34 times that of the standard, $\mathrm{Cd}$ is twice that of the standard, and other indicators are within the standards; (4) in industrial sewage, $\mathrm{Cl}^{-}$is 1.41 times that of the standard, $\mathrm{Cd}$ is 6.4 times that of the standard, $\mathrm{Pb}$ is 1.4 times that of the standard, $\mathrm{Cr}^{6+}$ is 2.28 times that of the standard, $\mathrm{Hg}$ is 2 times that of the standard, and other indicators are within the standard.

Nemerow index method (Tang et al. 2019) was applied for the comprehensive evaluation, and the comprehensive index values were compared against pollution level standards to conclude the pollution levels of the water quality. The com-

Table 1: Analysis methods for various indicators.

\begin{tabular}{|llll|}
\hline Item & Method & Item & Method \\
\hline $\mathrm{Cl}^{-}$ & Ion Chromatography & $\mathrm{Pb}$ & Inductively Coupled Plasma Mass Spectrometry \\
$\mathrm{F}^{-}$ & & $\mathrm{Zn}$ & \\
$\mathrm{TP}$ & & $\mathrm{Cu}$ & Atomic Fluorescence Spectrometry \\
$\mathrm{NO}_{3}-\mathrm{N}$ & & $\mathrm{As}$ & \\
$\mathrm{NH}_{3}-\mathrm{N}$ & & $\mathrm{Hg}$ & Graphite furnace Atomic Absorption Spectrometer \\
$\mathrm{NO}_{2}-\mathrm{N}$ & Spectrophotometry & $\mathrm{Cd}$ & \\
& & $\mathrm{Cr}^{6+}$ & \\
\hline
\end{tabular}


prehensive index PI used the following calculation formula:

$$
\begin{gathered}
P=\sqrt{\frac{\bar{I}^{2}+I_{\max }^{2}}{2}} \\
\bar{I}=\frac{1}{n} \sum_{i=1}^{n} I_{i} \\
I=\frac{C_{i}}{C_{0}}
\end{gathered}
$$

in which, $\bar{I}$ implies the average value of the pollution indexes of various indicators; $I_{\max }$ implies the maximum value of pollution indexes; PI implies the comprehensive pollution index, and $n$ implies the quantity of the indicators.

Based on the data from Table 2, the calculated comprehensive indexes are respectively: the comprehensive index of reclaimed water is 0.86 , domestic sewage is 1.45 , mixed sewage is 1.48 , and industrial sewage is 4.69 . The evaluation standards are $\mathrm{PI}<1.0$ - unpolluted; 1.0 $\mathrm{PI}<2.5$ - slightly polluted; $2.5 \mathrm{PI}<5$ - mediumly polluted, and; 5 PI - heavily polluted. The comparison results between the comprehensive indexes of various water quality and the evaluation standards are reclaimed water-unpolluted, domestic sewage and mixed sewage-slightly polluted, industrial sewage-moderately polluted. Based on the results of the comprehensive evaluation, the water quality of reclaimed water, domestic sewage and mixed sewage basically conform to the requirement of agricultural irrigation, and the pollution index of industrial sewage is quite high and not much suitable for agricultural irrigation.

Groundwater quality evaluation: To a certain extent, irrigation with sewage alleviates the problem of agricultural water shortage. But if you do not pay attention to the safety of irrigation sewage, the groundwater could be polluted (Peng et al. 2014). The pollutants enter into groundwater environment mainly through intermittent and infiltrative contamination, and the harmful ingredients enter into the aquifer through the leaching of precipitation or irrigation water (Bao 2014). Once the groundwater is polluted, treatment for it is more difficult than that for surface water. That is why people are paying more and more attention to the quality of groundwater.

Groundwater evaluation methods: Fuzzy comprehensive evaluation method was adopted to evaluate groundwater quality. Establishing the membership relation between the evaluation factors and evaluation standards based on membership grade is a way of formulating the borders of water quality classification (Fang et al. 2019), which demonstrates the fuzziness of water quality grades and reflects the comprehensive water quality categories very well, and makes the evaluation results more reasonable. Quality Standard for Ground Water (GBT14848-2017) was adopted as an evaluation factor standard, see Table 3 . In view of the situation of the irrigation areas and the principles for water quality evaluation, ammonia nitrogen $\left(\mathrm{NH}_{3}-\mathrm{N}\right)$, chloride $\mathrm{Cl}^{-}$, nitrate $\left(\mathrm{NO}_{3}-\mathrm{N}\right)$ and nitrite $\left(\mathrm{NO}_{2}-\mathrm{N}\right)$ were chosen as evaluation indicators. As the content of cadmium, lead, copper, zinc and mercury is relatively low in groundwater quality and lower than the detectable level, this time they were not included in the evaluation indicators.

Table 2: calculation results of pollution index of single indicators of different irrigation water quality.

\begin{tabular}{|lllllllllll}
\hline Indicator & $\mathrm{Cl}^{-}$ & $\mathrm{Cd}$ & $\mathrm{Pb}$ & $\mathrm{Cr}^{6+}$ & $\mathrm{As}$ & $\mathrm{Cu}$ & $\mathrm{F}^{-}$ & $\mathrm{TP}$ & $\mathrm{Hg}$ & $\mathrm{Zn}$ \\
\hline Standard Limit $\mathrm{C}_{0}$ & 250.000 & 0.005 & 0.100 & 0.100 & 0.050 & 1.000 & 3.000 & 5.000 & 0.001 & 2.000 \\
Reclaimed Water $\mathrm{C}_{1}$ & 84.600 & 0.006 & 0.000 & 0.012 & 0.000 & 0.000 & 0.644 & 0.000 & 0.000 & 0.000 \\
Pollution Index $\mathrm{I}_{1}$ & 0.338 & 1.200 & 0.000 & 0.120 & 0.000 & 0.000 & 0.215 & 0.000 & 0.200 & 0.000 \\
Domestic Sewage C & 86.200 & 0.003 & 0.200 & 0.004 & 0.000 & 0.025 & 0.826 & 1.820 & 0.001 & 0.117 \\
Pollution Index I & 0.345 & 0.600 & 2.000 & 0.040 & 0.002 & 0.025 & 0.275 & 0.364 & 1.000 & 0.059 \\
Mixed Sewage $\mathrm{C}_{3}$ & 335.000 & 0.010 & 0.080 & 0.052 & 0.005 & 0.078 & 0.982 & 0.610 & 0.000 & 0.610 \\
Pollution Index I & 1.340 & 2.000 & 0.800 & 0.520 & 0.100 & 0.078 & 0.327 & 0.122 & 0.400 & 0.305 \\
Industrial Sewage $\mathrm{C}_{4}$ & 285.350 & 0.032 & 0.140 & 0.228 & 0.167 & 0.103 & 0.765 & 0.350 & 0.002 & 0.396 \\
Pollution Index $\mathrm{I}_{4}$ & 1.141 & 6.400 & 1.400 & 2.280 & 3.340 & 0.103 & 0.255 & 0.070 & 2.000 & 0.198 \\
\hline
\end{tabular}

Table 3: Groundwater evaluation factor standard.

\begin{tabular}{|llllll|}
\hline Project & I & II & III & IV & V \\
\hline $\mathrm{NH}_{3}-\mathrm{N}$ & 0.02 & 0.1 & 0.5 & 1.5 & $>1.5$ \\
$\mathrm{Cl}^{-}$ & 50 & 150 & 250 & 350 & $>350$ \\
$\mathrm{NO}_{3}-\mathrm{N}$ & 2 & 5 & 20 & 30 & $>3.8$ \\
$\mathrm{NO}_{2}-\mathrm{N}$ & $<0.01$ & 0.1 & 1 & & $>4.8$ \\
\hline
\end{tabular}


Major steps of Fuzzy comprehensive evaluation are:

(1) Define the target grades: Based on the different status of the evaluation objects, define $\mathrm{m}$ evaluation grades, which are recorded as:

$$
V=\left\{v_{1}, v_{2}, \ldots, v_{m}\right\}
$$

(2) Establish an evaluation indicator set: Based on the situation of the evaluation objects, choose $n$ typical evaluation factors and form the indicator set:

$$
U=\left\{u_{1}, u_{2}, \ldots, u_{n}\right\}
$$

(3) Establish a membership grade function: Calculate the membership grade of each evaluation factor $u_{i}$ vs. evaluation grade $v_{i}$, and establish a fuzzy relation matrix R.

$$
R=\left[\begin{array}{cccc}
r_{11} & r_{12} & \cdots & r_{1 m} \\
r_{21} & r_{22} & \cdots & r_{2 m} \\
\vdots & \vdots & \ddots & \vdots \\
r_{a 1} & r_{a 2} & \cdots & r_{a m}
\end{array}\right]
$$

In the formula, $m$ implies evaluation grade and implies the number of evaluation indicators.

$$
\begin{gathered}
r_{i 1}=\left\{\begin{array}{cc}
1 & x \leq x_{1} \\
\frac{x_{2}-x}{x_{2}-x_{1}} & x_{1}<x<x_{2} \\
0 & x>x_{2}
\end{array}\right. \\
r_{i 2}=\left\{\begin{array}{cc}
0 & x \leq x_{1} \text { or } x>x_{3} \\
\frac{x-x_{1}}{x_{2}-x_{1}} & x_{1}<x \leq x_{2} \\
\frac{x_{3}-x}{x_{3}-x_{2}} & x_{2}<x \leq x_{3}
\end{array}\right. \\
r_{i 3}=\left\{\begin{array}{cc}
0 & x \leq x_{2} \text { or } x \geq x_{4} \\
\frac{x-x_{2}}{x_{3}-x_{2}} & x_{2}<x \leq x_{3} \\
\frac{x_{4}-x}{x_{4}-x_{3}} & x_{3}<x \leq x_{4}
\end{array}\right. \\
r_{i 4}=\left\{\begin{array}{cc}
\frac{x-x_{3}}{x_{4}-x_{3}} & x_{3}<x \leq x_{4} \\
\frac{x_{5}-x}{x_{5}-x_{4}} & x_{4}<x \leq x_{5}
\end{array}\right.
\end{gathered}
$$

$$
r_{i 5}=\left\{\begin{array}{cc}
0 & x \leq x_{4} \\
\frac{x-x_{4}}{x_{2}-x_{1}} & x_{4}<x<x_{5} \\
1 & x>x_{5}
\end{array}\right.
$$

In the formula, $X_{1}, X_{2}, \ldots X_{5}$ imply the boundary values of water quality standard grades of the evaluation factor indicators, and $X$ implies the measured values of various evaluation factors.

(4) Define the weights: as this article uses a multiple indicator system for a comprehensive evaluation, to reflect the interaction between indications more directly, entropy method (Xie 2016) is adopted to define the weights, i.e. defining the weights of various indicators based on the difference of the measured values of various indicators.

(5) Establish data matrix

$$
S=\left[\begin{array}{ccc}
x_{11} & \cdots & x_{1 a} \\
\vdots & \ddots & \vdots \\
x_{n 1} & \cdots & x_{n a}
\end{array}\right]_{n \times a}
$$

In the formula, $X_{i j}$ implies the value of Indicator $\# \mathrm{j}$ of Plan \#i, $n$ implies the quantity of evaluation samples, and $a$ implies the quantity of evaluation indicators.

(6) Calculate the specific gravity of Plan \#i under Indicator $\# \mathrm{j}$ in the indicators.

$$
P_{i j}=\frac{x_{i j}}{\sum_{i=1}^{n} x_{i j}}(\mathrm{j}=1,2, \cdots \mathrm{a})
$$

(7) Define the entropy value of the evaluation factor $E_{i j}$

$$
E_{i j}=-\left(\sum_{i=1}^{m} p_{i j} \operatorname{In} p_{i j}\right) / \mathrm{In} n
$$

(8) Define the weight of evaluation factors

$$
w_{j}=E_{i} / \sum_{j=1}^{a} E_{i}
$$

Get the weight matrix $\mathrm{A}=\left(w_{1}, w_{2} \ldots w_{a}\right)$

(9) Define the evaluation grades: Composite calculation with weight matrix A and fuzzy relation matrix $\mathrm{R}$ to get the comprehensive membership grade vector $\mathrm{B}$ of the evaluation object.

$$
B=A \cdot R=\left[b_{1}, b_{2}, \cdots, b_{m}\right]
$$

Normalization processing on vector $\mathrm{B}$, and get the grade of the evaluation object based on the value of $\mathrm{H}$.

$$
\left.H=\sum_{j=1}^{m}\left[\left(b_{j} / \sum_{j=1}^{m} b_{j}\right) \times j\right)\right]
$$


Results of the comprehensive evaluation: Adopting Quality Standard for Ground Water (GBT14848-2017) as evaluation factor standard, the groundwater quality was divided into 5 grades. Fuzzy relation matrix $\mathrm{R}$ for the water quality samples of 11 groundwater monitor wells was established respectively, taking Monitor Well \# 1 as an example.

$$
R=\left[\begin{array}{lllll}
0.000 & 0.675 & 0.325 & 0.000 & 0.000 \\
0.720 & 0.280 & 0.000 & 0.000 & 0.000 \\
0.377 & 0.623 & 0.000 & 0.000 & 0.000 \\
0.967 & 0.033 & 0.000 & 0.000 & 0.000
\end{array}\right]
$$

In the formula, Line 1 represents the relative membership grade values of ammonia nitrogen corresponding to 5 grades, which are Grade I to Grade V from the left to the right; Line 2 to Line 4 are $\mathrm{Cl}^{-}, \mathrm{NO}_{3}-\mathrm{N}, \mathrm{NO}_{2}-\mathrm{N}$ in turn.

The respective weights of the evaluation indicators, i.e. ammonia nitrogen $\left(\mathrm{NH}_{3}-\mathrm{N}\right)$, chloride $\mathrm{Cl}^{-}$, nitrate $\left(\mathrm{NO}_{3}-\mathrm{N}\right)$ and nitrite $\left(\mathrm{NO}_{2}-\mathrm{N}\right)$ were defined in the water quality samples with entropy evaluation method, which are $0.364,0.165$, 0.253 and 0.218 respectively.

Based on the water quality monitoring data of the 11 groundwater monitor wells chosen in the study area, fuzzy mathematics comprehensive evaluation model was applied to get the water quality evaluation results as given in Table 4 .

According to the comprehensive evaluation results, among the water quality results of the 11 groundwater monitor wells from different irrigation water sources, the water in 2 monitor wells belongs to Water Category II, the water in 6 monitor wells belongs to Water Category III, and the water in 3 monitor wells belongs to Water Category IV. Taking monitor well \#1 as an example, the comprehensive evaluation result on water quality of the \#1 monitor well is within Category II, as among the single evaluation indicators, ammonia nitrogen is within Category III, while chloride, nitrate and nitrite are within Category II, therefore it is rea- sonable to tell with the fuzzy comprehensive evaluation that the water in \# 1 monitor well belongs to Water Category II.

The monitor wells \#1 and \#2 are located in the reclaimed water irrigation area, and the fuzzy comprehensive evaluation result is Category II; \#3 and \#4 monitor wells are located in the domestic sewage irrigation area, and the fuzzy comprehensive evaluation result is Category III; \#5-7 are located in the mixed sewage irrigation area, and the fuzzy comprehensive evaluation result is Category III, and; \#8-11 are located in the industrial sewage irrigation area, and the fuzzy comprehensive evaluation result is Category III for \#10, and Category IV for the rest of 3 wells. In terms of the effect of different irrigation water sources on the groundwater, the comprehensive evaluation results are reasonable as well. Based on comprehensive membership grades, we can tell that the effect levels of different irrigation water sources on the groundwater are, in turn, reclaimed water $<$ domestic sewage $<$ mixed sewage $<$ industrial sewage, which is line with the pollution levels of the sewage on the water quality when irrigating. Therefore, the method of evaluating groundwater quality with fuzzy comprehensive evaluation is feasible.

The effect of irrigation with reclaimed water on the water quality of groundwater is relatively small; the impact of domestic sewage and mixed sewage is relatively big, and; the effect of industrial sewage on groundwater is quite high, in which the groundwater quality reaches Category IV, which causes severe pollution of the groundwater. From the comprehensive evaluation results, we can conclude that the groundwater in the study areas has been contaminated to different extent. Therefore, if sewage irrigation is adopted in places where there is a shortage of water resources, sewage water quality management should be strengthened, especially with regards to the discharge of industrial sewage which should not be discharged until it is up to the discharge standard, and domestic sewage should be treated and discharged in a concentrated way, to avoid serious impact on groundwater quality.

Table 4: Fuzzy comprehensive evaluation results of groundwater quality of various monitor wells.

\begin{tabular}{|lllllllll|}
\hline Minor well number & I & II & III & IV & V & H & Water quality classification \\
\hline 1 & 0.425 & 0.457 & 0.118 & 0.000 & 0.000 & 1.694 & II \\
2 & 0.451 & 0.549 & 0.000 & 0.000 & 0.000 & 1.549 & II \\
3 & 0.408 & 0.326 & 0.100 & 0.000 & 0.165 & 2.188 & III \\
4 & 0.291 & 0.353 & 0.327 & 0.030 & 0.000 & 2.096 & III \\
5 & 0.417 & 0.099 & 0.319 & 0.000 & 0.165 & 2.398 & III \\
6 & 0.365 & 0.393 & 0.077 & 0.000 & 0.165 & 2.208 & III \\
7 & 0.367 & 0.331 & 0.137 & 0.000 & 0.165 & 2.266 & III \\
8 & 0.218 & 0.044 & 0.351 & 0.222 & 0.165 & 3.074 & IV \\
9 & 0.213 & 0.187 & 0.104 & 0.331 & 0.165 & 3.050 & IV \\
10 & 0.218 & 0.098 & 0.263 & 0.422 & 0.000 & 2.889 & III \\
11 & 0.218 & 0.137 & 0.109 & 0.172 & 0.364 & 3.327 & IV \\
\hline
\end{tabular}




\section{CONCLUSIONS}

Sewage irrigation can alleviate the shortage of irrigation water and solve the problem of shortage of water resources, but long-term use of untreated sewage for irrigation will cause problems such as soil pollution, impact on crop growth, groundwater quality decline and so on. Compared with dry farming, irrigation on crops with sewage can increase the yield of crops to a certain extent, but the impact on soil, crops and groundwater should not be ignored. As long as scientific irrigation method is adopted, sewage water is utilized properly, and the harm caused by sewage is controlled within the acceptable safety range, the sewage can be used in agricultural irrigation safely and efficiently. For different water sources, different soil types and different crops, suitable irrigation system and irrigation methods should be adopted. The establishment of a reasonable and comprehensive safety evaluation system will provide a theoretical basis for the proper management of sewage irrigation. Developing high efficiency and energy saving sewage treatment technology will reduce treatment cost and promote sewage irrigation.

Using sewage irrigation safely and properly can not only alleviate the contradiction between supply and demand for water resources but also protect the ecological environment and support the sustainable development of water resources.

\section{REFERENCES}

Bao, Z. 2014. Research on pollution risk of heavy metals in soil and groundwater under reclaimed water irrigation. China University of Geosciences (Beijing), pp. 91-93.

Fang, Y.H., Zheng, X.L., Peng, H., Wang, H., Xin, J. and Zhang, B. 2019. Groundwater quality assessment based on optimization of fuzzy synthetic evaluation. Earth Science Frontiers, 26(4): 301-306.

Peng, S.Z., Cheng, S., Xu, J.Z. and Xiong, Y.J. 2014. Advances in safe utilization of poor-quality water. Water Resources Protection, 30(4): 1-6.

Tang, Y.Q., Li, Q.W., Zuo, W.L. and Wang, J. 2019. Analysis of applicability of Nemerow index method in evaluation of water quality of Beidaihe national wetland park. Environmental Engineering, 37(8): 195-199, 189.

Wan, L., Zhang, M.Y., Lu, S. and Hu, K. 2015. Study progress on effect of polluted water irrigation on soil and problem analysis. Ecology and Environmental Sciences, 24(5): 906-910.

Wen, X.G. 2012. Study on groundwater environment impact by reclaimed water irrigation in Beijing NanHongmen. Tsinghua University, pp. 37-38.

Xie, F. 2016. The groundwater quality assessment and response of different irrigation water sources to groundwater in Jinghuiqu irrigation district. Northwest A\&F University, pp. 27-31. 